\title{
Modeling of Compressive Strength of Concrete using Gaussian Membership Function
}

\author{
M. Deepak, M. Balamurali, P. Vinoth, J. Jeeva Bharathi, K. Kapilaravindh
}

\begin{abstract}
This paper presents an application of fuzzy logic to forecast the compressive strength of concrete. The fuzzy model examines 7 different input parameters that comprises: Cement, Coarse aggregate(CA), Super plasticizer(SP), Fine Aggregate(FA), Slag, Fly ash, Water $(W)$, and 28 days compressive strength is taken as the output parameter. By using Gaussian membership function, the fuzzy logic technique is used for developing models. For assessing the results of FL model with experimental results, root mean square error, mean absolute error and correlation coefficient are used. The results showed that FL can be a better modeling tool and an another technique for predicting the concrete's compressive strength.
\end{abstract}

Keywords: Fuzzy Logic, Gaussian membership function, Compressive strength, Concrete.

\section{INTRODUCTION}

$T_{\text {his Concrete is a material which consists of binder and }}$ aggregate particles combined together. [1] The strength of concrete grows as the days getting older in usual circumstances. It takes time to combine the aggregates and solidify the paste which is caused by reactions by cement and concrete. Initially reactions takes place rapidly after that gradually over a period of time [2]. Innovation come on partial substitution of cement with waste by-products like fly ash or ground granulated blast furnace slag (GGBFS) have growing, to reduce the disposal of waste by-products [4]. It is well acknowledged that pozzolana like, silica fume, fly ash, and GGBFS are industrial derived products that present excessive discrepancies of properties, which can occasionally compromise their use [5]. These pozzolanic materials are used as admixtures in cement and concrete production to minimize the cement content. [6]. Fly ash up to $60 \%$ can be used, if the early strength is not an crucial fact. Since, at early ages fly ash usually results in undesirable effects on the concrete strength $[7,8]$. For dipping the cracking and heat of hydration at primary ages in concrete, fly ash obtained from coal-fired power plants can be utilized. The compressive strength for long-term and longevity can be achieved with concrete in concrete structures containing fly

ash [4]. The concrete containing fly ashes are prepared at lesser of water to binder ratios to obtain enhanced strength and durability performance.

Revised Manuscript Received on December 30, 2019.

* Correspondence Author

First Author Mr. M. Deepak*. Assistant Professor, Department of Civil Engineering, Karpagam College of Engineering, Coimbatore, Tamil Nadu, India. Email: mdmyid@gmail.com

Second Author Balamurali .M, B.E.Final year student, Department of Civil Engineering, Karpagam College of Engineering, Coimbatore, Tamil Nadu, India.
Generally the compressive strength test are performed at 7 as well as 28 days with the date of casting. Normally after 28 days testing are done and can be also done at different ages according to the necessity. [9-12].

Nowadays many researchers use widespread data exploration techniques such as artificial neural network, fuzzy logic, for all varieties of engineering applications. The primary driving force for presenting fuzzy concepts is to express the uncertain concepts. It requires a straightforward method based on engineering expertise to manage the complicated mathematical models. It is simple and comfortable to work with fuzzy logic for examining the impacts of individual variable on the proportion of mix in numerical experiments. [9-12]

\section{FUZZY LOGIC}

Zadeh established the idea of "fuzzy Logic" [13]. FL idea offers a method of handling with problems where the basis of fuzziness is the lack of definite described conditions $[10,14]$. Fuzzy logic offers an efficient calculus to interact with many of these data Ideally. Utilizing linguistic labels simulated simply by membership functions, Fuzzy approach performs numerical computation [15].

The important thing in fuzzy logic is the grant of limited properties of various kind of stuffs with the purpose of diverse subsets of the widespread set as an alternative of fitting to a only one set totally. Limited properties to a set can be defined mathematically with a membership function that adopts standards that have among 0 and 1 , angular fuzzy sets, Intuition, rank purchasing, inference, neural networks and inductive thinking are the various methods to assign regular membership values. For example, figure 1 depicts a distinctive membership function with class sizes small, medium , and large proposed in a universal set, $\mathrm{U}$. The figure shows the values lying below 2 are considered "small", those ranging from 4 to 6 are considered "medium" and those values above 8 are considered absolutely "large". But, in-between values for example 2.3 are the part of the subsets to some extent. According to fuzzy concepts, 2.3 has a membership function value of 0.0 in "large", however 0.9 in "small" and 0.1 in "medium" subsets. [10, 14, 16, 25] 


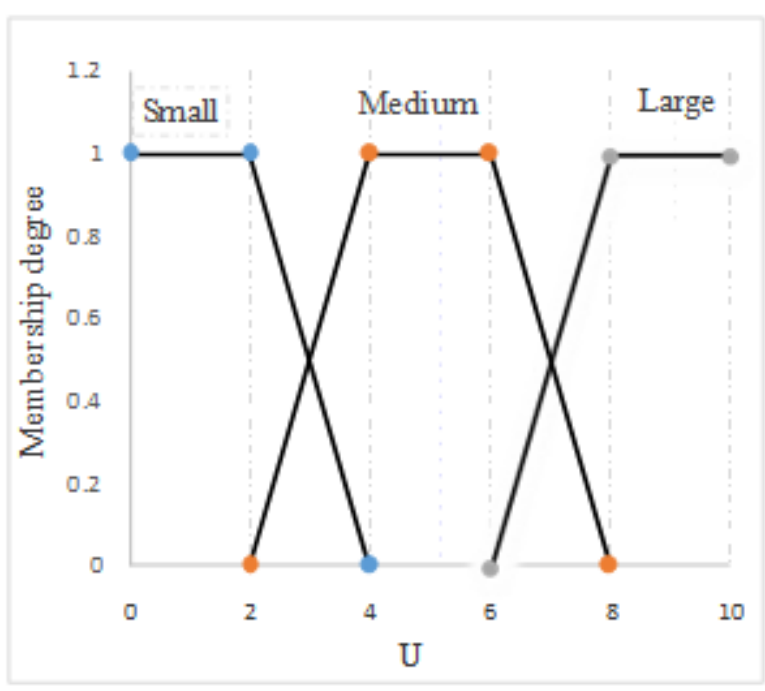

Figure 1: A Typical Membership Function

A common fuzzy inference system (FIS) has fundamentally four parts:

(1) Fuzzy rule base

(2) Fuzzification

(3) Defuzzification

(4) Fuzzy output engine

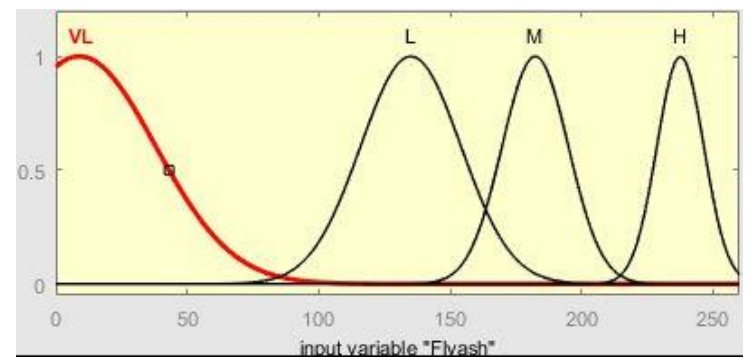

Figure 2: Diagrammatic Representation of Fuzzy System

Figure 2 displays the diagrammatic representation of fuzzy system. Fuzzification means all the input values are transformed to degrees of membership by searching more number of membership functions. all feasible relations that is the relation between the input and output are available in Fuzzy rule base. These rules are defined in the IF-THEN format. Mamdani type, and Sugeno type are the mainly two type of rule base, every fuzzy rules in the fuzzy rule base acquires knowledge on in what way to change a set of inputs to the equivalent outputs are taken into account by Fuzzy inference engine, product (prod) and minimization (min) are the two types of inference operators. From the fuzzy inference engine, defuzzification transforms the fuzzy output into a number. centroid, rightmost maximum, mean of maxima, leftmost maximum, bisector of area are the numerous defuzzification methods. Parameter prediction and Structure identification are the two stages in Fuzzy modeling involving in identification task. choosing the related input variables, picking a particular kind of FIS, defining their antecedents and consequents, and the number of fuzzy rules, and evaluating the number of membership functions and its type are the issues included in structure identification. Ascertainment of targeted values response to apparent input values of incorporated model, are included in parameter forecasting. For this purpose 35 data results have been used in the fuzzy model and they were displayed in table I. Training the model means to give the data so that it will learn and provides the output that is strength.

In the current study, the mamdani fuzzy rule type is used to create the fuzzy model and the min method was chosen due to its more accurate results. For defuzzification of the fuzzy output, centroid method was implemented. Membership functions would be the essential part of the fuzzy logic. Based on ranges and variability of input and output data the membership functions were equipped accordingly. Gaussian membership function was chosen. The Gaussian membership functions for various variables are displayed in Figure 3 $(\mathrm{a}-\mathrm{h})$. The ranges of the variables were given is table II and the fuzzy rule sets in table III.

The seven major variables used for FL are water, fine aggregate, SP ,Cement, Coarse aggregate, Slag .[24].

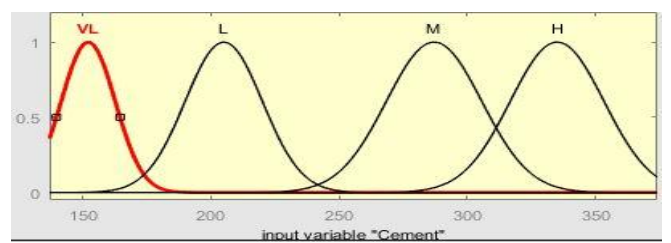

Figure 3a: Membership Function of Cement

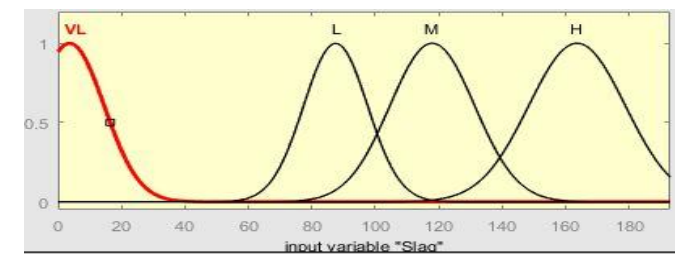

Figure3b: Membership Function of Slag

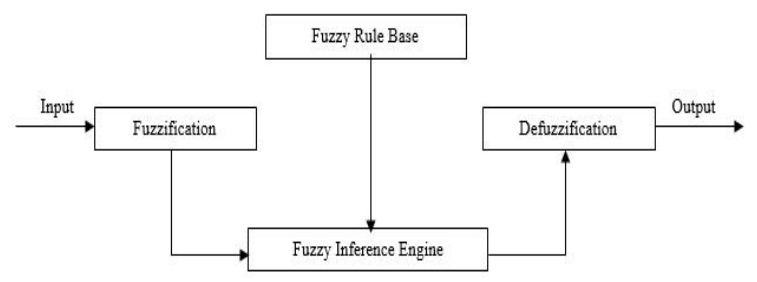

Figure3c: Membership Function of Fly Ash

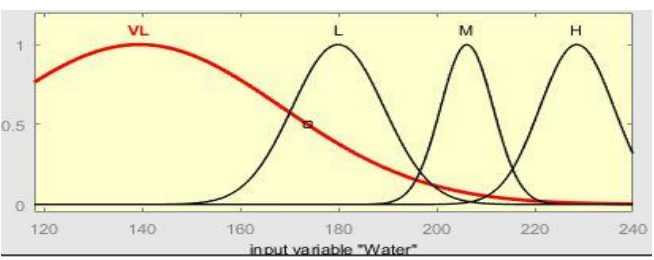

Figure 3d: Membership Function of Water 


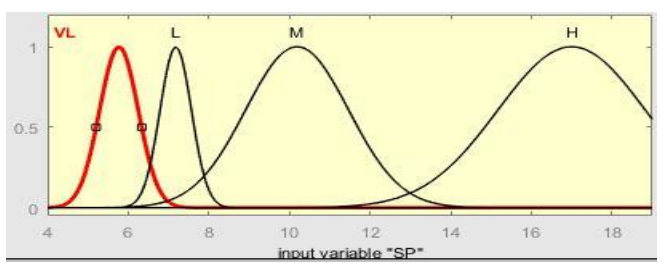

Figure 3e:Membership Function of Super Plasticizer

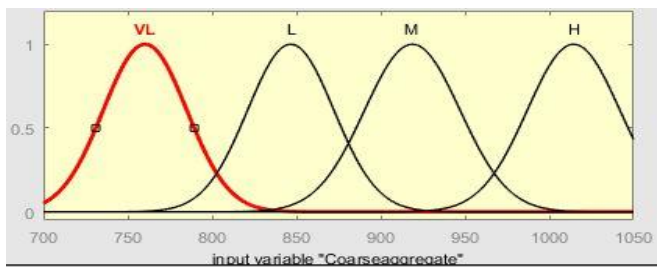

Figure 3f: Membership Function of Coarse Aggregate

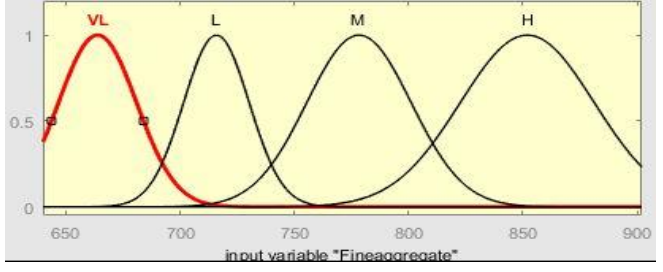

Figure 3g: Membership Function of Fine Aggregate

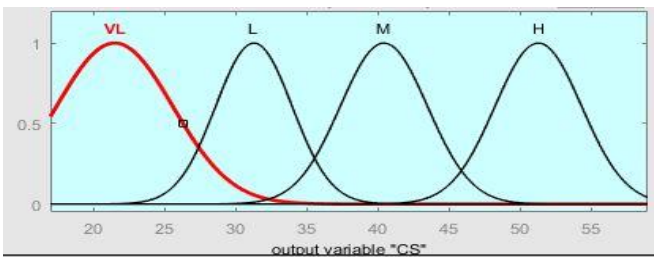

Figure 3h: Membership Function of Compressive Strength

Table- I: Particulars of data used in modeling

\begin{tabular}{|c|c|c|c|c|c|c|c|c|}
\hline \multirow[b]{2}{*}{ Cement } & \multirow[b]{2}{*}{ Slag } & \multirow[b]{2}{*}{ FA } & \multirow[b]{2}{*}{ Water } & \multirow[b]{2}{*}{ SP } & \multirow[b]{2}{*}{ CA } & \multirow[b]{2}{*}{ FA } & \multicolumn{2}{|c|}{ Compressive Strength at 28 days } \\
\hline & & & & & & & $\begin{array}{c}\text { Measured } \\
\text { strength }\end{array}$ & $\begin{array}{l}\text { Predicted } \\
\text { strength }\end{array}$ \\
\hline 140 & 150 & 0 & 182 & 12 & 1023 & 729 & 18.26 & 23.3 \\
\hline 149 & 112 & 144 & 220 & 10 & 923 & 658 & 26.82 & 29.8 \\
\hline 145 & 105 & 0 & 205 & 6 & 859 & 797 & 27.62 & 27.6 \\
\hline 146 & 106 & 137 & 209 & 6 & 875 & 765 & 27.89 & 32.9 \\
\hline 142 & 112 & 0 & 220 & 10 & 794 & 789 & 28.16 & 28.6 \\
\hline 147 & 107 & 0 & 210 & 10 & 881 & 745 & 28.29 & 27.3 \\
\hline 150.3 & 97 & 0 & 219 & 9 & 932 & 685 & 29.23 & 28.6 \\
\hline 143.3 & 124 & 0 & 205 & 11 & 846 & 758 & 29.63 & 25.4 \\
\hline 143 & 116 & 0 & 196 & 10 & 818 & 813 & 29.77 & 28.2 \\
\hline 150.4 & 100 & 0 & 196 & 10 & 959 & 705 & 29.77 & 27.3 \\
\hline 152 & 0.6 & 209.5 & 118.8 & 4.6 & 996.1 & 789.2 & 30.43 & 30.7 \\
\hline 145 & 104 & 0 & 231 & 9 & 857 & 725 & 30.43 & 33.4 \\
\hline 154 & 1.4 & 198.1 & 174.9 & 4.4 & 1049.9 & 780.5 & 30.83 & 33.4 \\
\hline 148 & 110 & 0 & 189 & 10 & 904 & 765 & 31.5 & 26.9 \\
\hline 166 & 126 & 0 & 210 & 6 & 861 & 737 & 31.77 & 26.5 \\
\hline 159 & 136 & 0 & 225 & 11 & 770 & 747 & 32.04 & 30.3 \\
\hline 162 & 141 & 181 & 234 & 11 & 797 & 683 & 33.51 & 37.5 \\
\hline
\end{tabular}


Modeling of Compressive Strength of Concrete using Gaussian Membership Function

\begin{tabular}{|c|c|c|c|c|c|c|c|c|}
\hline 158 & 0 & 227 & 240 & 6 & 750 & 853 & 36.59 & 39.9 \\
\hline 291 & 106 & 136 & 206 & 11 & 750 & 766 & 41.01 & 45.9 \\
\hline 296 & 149 & 191 & 180 & 12 & 843 & 746 & 41.14 & 45.8 \\
\hline 299 & 107 & 137 & 201 & 6 & 878 & 655 & 41.27 & 46.8 \\
\hline 295.3 & 148 & 191 & 179 & 16 & 840 & 743 & 41.81 & 45.9 \\
\hline 295 & 148 & 190 & 179 & 19 & 838 & 741 & 42.08 & 44.5 \\
\hline 295 & 111 & 142 & 217 & 10 & 783 & 686 & 42.08 & 45.9 \\
\hline 305 & 94 & 121 & 188 & 9 & 904 & 696 & 43.01 & 44.9 \\
\hline 321 & 99 & 127 & 184 & 13 & 810 & 790 & 43.54 & 43.3 \\
\hline 320 & 0 & 178 & 230 & 6 & 785 & 721 & 43.95 & 46.8 \\
\hline 326 & 90 & 116 & 180 & 9 & 870 & 768 & 44.08 & 44.8 \\
\hline 320 & 0 & 239.9 & 236.2 & 8.3 & 780.3 & 722.9 & 44.08 & 46.4 \\
\hline 318 & 0.2 & 239.8 & 236.4 & 8.3 & 780.1 & 715.3 & 44.48 & 46.4 \\
\hline 348.7 & 40.9 & 239.9 & 194 & 7.5 & 908.9 & 651.8 & 49.19 & 49.6 \\
\hline 349 & 0 & 143 & 168 & 10 & 914 & 804 & 49.3 & 50.7 \\
\hline 354 & 88 & 239.6 & 175.3 & 7.6 & 938.9 & 646 & 50.5 & 51.3 \\
\hline 342 & 0 & 167 & 174 & 6 & 884 & 792 & 52.65 & 49.8 \\
\hline 336 & 0 & 187 & 191 & 7 & 824 & 757 & 52.65 & 50.6 \\
\hline
\end{tabular}

Table II: Range of variables in database

\begin{tabular}{|c|c|c|c|c|}
\hline \multirow[t]{2}{*}{ Variables } & \multirow[t]{2}{*}{ Parameters } & \multirow[t]{2}{*}{ Abbreviation } & \multicolumn{2}{|c|}{ Range of Database } \\
\hline & & & Minimum & Maximum \\
\hline \multirow[t]{7}{*}{ Input } & Cement $\left(\mathrm{kg} / \mathrm{m}^{3}\right)$ & $\mathrm{C}$ & 137 & 374 \\
\hline & Water $\left(\mathrm{kg} / \mathrm{m}^{3}\right)$ & $\mathrm{W}$ & 118.8 & 240 \\
\hline & Fine Aggregate $\left(\mathrm{kg} / \mathrm{m}^{3}\right)$ & FA & 640.6 & 902 \\
\hline & Coarse Aggregate $\left(\mathrm{kg} / \mathrm{m}^{3}\right)$ & $\mathrm{CA}$ & 708 & 1049.9 \\
\hline & Fly ash $\left(\mathrm{kg} / \mathrm{m}^{3}\right)$ & $\mathrm{FH}$ & 0 & 260 \\
\hline & Super plasticizer $\left(\mathrm{kg} / \mathrm{m}^{3}\right)$ & SP & 4.4 & 19 \\
\hline & $\operatorname{Slag}\left(\mathrm{kg} / \mathrm{m}^{3}\right)$ & $S$ & 0 & 193 \\
\hline Output & $\begin{array}{l}\text { Compressive Strength } 28 \\
\text { days(MPa) }\end{array}$ & $\mathrm{CS}$ & 17.19 & 58.53 \\
\hline
\end{tabular}

Table III: The Fuzzy Rule Sets

\begin{tabular}{|c|c|c|c|c|c|c|c|c|}
\hline $\begin{array}{c}\text { Rule } \\
\text { Number }\end{array}$ & Cement & Slag & $\begin{array}{c}\text { Fly } \\
\text { ash }\end{array}$ & Water & SP & CA & FA & $\begin{array}{c}\text { Compressive } \\
\text { strength }\end{array}$ \\
\hline 1 & VL & H & VL & L & M & M & M & VL \\
\hline 2 & VL & H & VL & L & M & H & L & \\
\hline
\end{tabular}




\begin{tabular}{|c|c|c|c|c|c|c|c|c|}
\hline 3 & VL & $\mathrm{H}$ & VL & $\mathrm{L}$ & M & $\mathrm{H}$ & $\mathrm{M}$ & VL \\
\hline 4 & VL & $\mathrm{L}$ & $\mathrm{L}$ & M & M & $\mathrm{L}$ & $\mathrm{H}$ & $\mathrm{L}$ \\
\hline 5 & $\mathrm{VL}$ & $M$ & $\mathrm{~L}$ & $\bar{M}$ & $\mathrm{M}$ & VL & $\mathrm{H}$ & $\mathrm{L}$ \\
\hline 6 & VL & VL & $\mathrm{H}$ & $\mathrm{M}$ & VL & $\mathrm{H}$ & VL & $\mathrm{L}$ \\
\hline 7 & VL & M & $\mathrm{M}$ & M & VL & M & VL & $\mathrm{M}$ \\
\hline 8 & VL & VL & $\mathrm{L}$ & $\mathrm{M}$ & $\mathrm{M}$ & $\mathrm{L}$ & $\mathrm{M}$ & $\mathrm{M}$ \\
\hline 9 & $\mathrm{~L}$ & $\mathrm{M}$ & $\mathrm{H}$ & $\bar{M}$ & $\mathrm{~L}$ & $M$ & VL & $\mathrm{M}$ \\
\hline 10 & $\mathrm{~L}$ & $\mathrm{M}$ & $\mathrm{M}$ & $\mathrm{L}$ & $\mathrm{M}$ & $\mathrm{M}$ & $\mathrm{M}$ & $\mathrm{H}$ \\
\hline 11 & $\mathrm{M}$ & $\mathrm{H}$ & $\mathrm{H}$ & $\mathrm{L}$ & L & M & VL & $\mathrm{H}$ \\
\hline 12 & $\mathrm{M}$ & $M$ & $\mathrm{~L}$ & $\mathrm{M}$ & $\mathrm{VL}$ & $\mathrm{VL}$ & $\mathrm{M}$ & $\mathrm{H}$ \\
\hline 13 & $\mathrm{H}$ & $\mathrm{H}$ & $\mathrm{H}$ & $\mathrm{L}$ & $\mathrm{L}$ & $\mathrm{M}$ & VL & $\mathrm{H}$ \\
\hline 14 & $\mathrm{M}$ & $\mathrm{H}$ & $\mathrm{H}$ & $\mathrm{L}$ & $\mathrm{L}$ & $\mathrm{M}$ & VL & $\mathrm{H}$ \\
\hline 15 & $\mathrm{H}$ & VL & $\mathrm{L}$ & $\mathrm{L}$ & $M$ & $M$ & $\mathrm{~L}$ & $\mathrm{H}$ \\
\hline 16 & $\mathrm{H}$ & $\mathrm{VL}$ & $\mathrm{L}$ & $\mathrm{L}$ & $M$ & $\mathrm{~L}$ & $\mathrm{M}$ & $\mathrm{H}$ \\
\hline 17 & $\mathrm{H}$ & VL & $\mathrm{L}$ & $\mathrm{L}$ & VL & $\mathrm{L}$ & $\mathrm{L}$ & $\mathrm{H}$ \\
\hline 18 & $\mathrm{H}$ & VL & $\mathrm{H}$ & M & $\mathrm{M}$ & VL & $\mathrm{M}$ & $\mathrm{H}$ \\
\hline 19 & $\mathrm{H}$ & $\mathrm{VL}$ & $\mathrm{H}$ & $\mathrm{L}$ & $\mathrm{L}$ & $\mathrm{M}$ & VL & $\mathrm{H}$ \\
\hline
\end{tabular}

\section{RESULT AND DISCUSSION}

The surface diagrams is used to show off the relationship between input or output variables, and the variation can be visualized more clearly by plotting a graph between input and output values The surface diagrams denotes different input and corresponding output parameters is denoted in Figure 4a and $4 \mathrm{~b}$. The efficiency of the model is solely depend on counteract between the model and input data. Figure 5 represents the predicted and the actual values of 28 days compressive strength of concrete comprising different percentage as a substitute of cement with fly ash and slag. Table IV shows the results of statistical parameters, like the root mean squared error (RMSE), the correlation coefficient (CC), and the mean absolute error (MAE) which are performed to have a comparison between predicted and actual values. The RMSE will be upward of or equivalent to MAE at all times; The wide discrepancy between them indicates the greater change in the individual errors in the data-set. 0.949837 is the correlation coefficient of the given data set. The value acquired from $\mathrm{CC}$ ensures that compressive strength have a positive correlation. Reducing the values of MAE nearer to zero makes the better fuzzy model. For obtaining good fuzzy model RMSE values must be smaller. The predictive effectiveness of the model can be measured by RMSE. [24]
Table IV: Statistical Results for the Fuzzy Logic Model

\begin{tabular}{|l|l|l|}
\hline S.No. & Statistical parameters & Values \\
\hline 1 & $\begin{array}{l}\text { Correlation Coefficient } \\
(\mathrm{CC})\end{array}$ & 0.949837 \\
\hline 2 & $\begin{array}{l}\text { Root Mean Square Error } \\
\text { (RMSE) }\end{array}$ & 3.077871 \\
\hline 3 & $\begin{array}{l}\text { Mean Absolute Error } \\
\text { (MAE) }\end{array}$ & 1.075429 \\
\hline
\end{tabular}

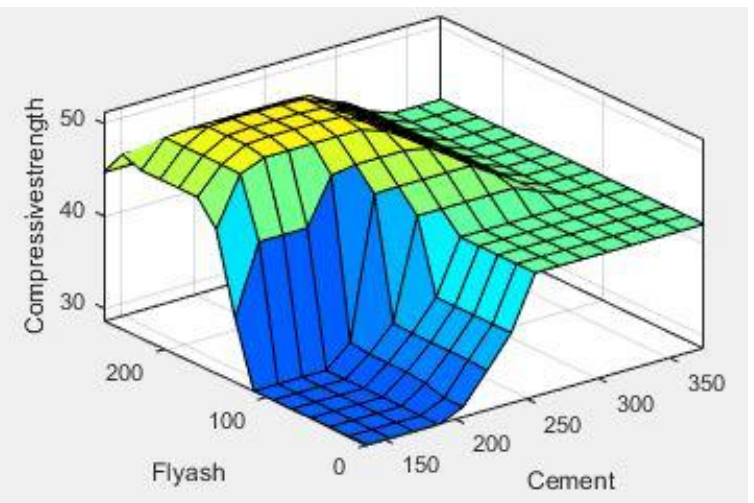

Figure 4a: Surface diagram among Cement, Fly Ash and Compressive Strength 


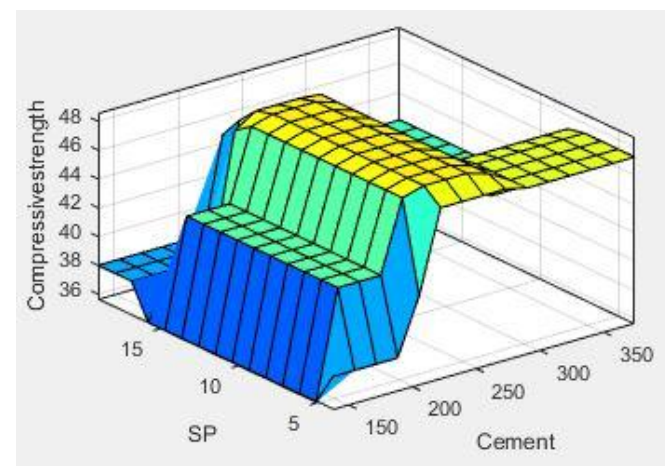

Figure 4b: Surface diagram among Cement, SP and Compressive Strength

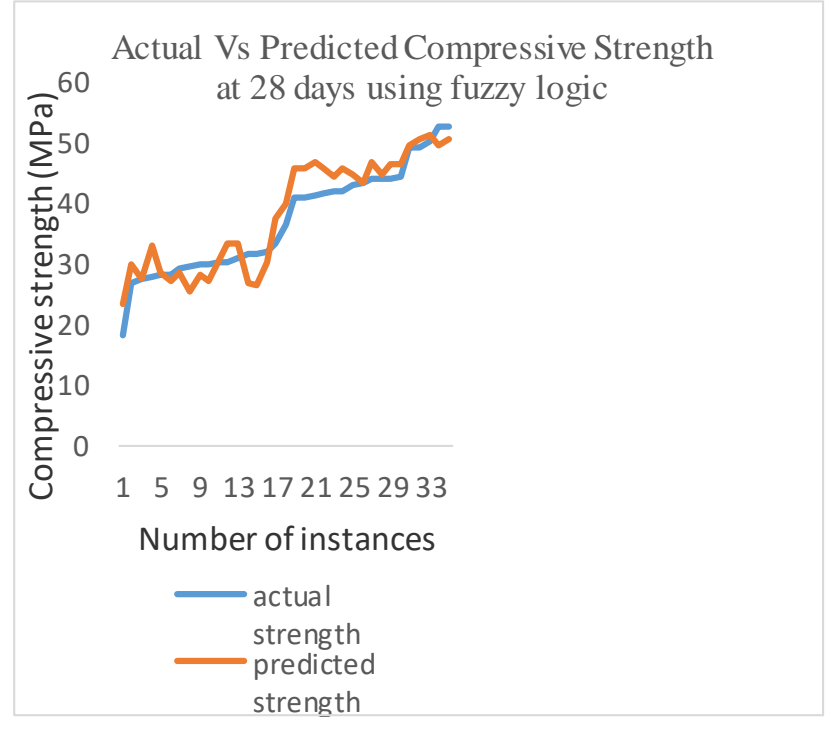

Figure 5: Results of Actual Vs. Predicted Strength at 28 days using Fuzzy Logic

\section{IV.CONCLUSION}

In the present work, an FL model was created for predicting 28 days compressive strength of concrete. The experimental outcomes are bit closer to the results acquired from FL models. The Correlation coefficient is 0.949837 which is nearing 1 shows that the correlation among the predicted and actual values. The values of RMSE and MAE were calculated as 1.075429 and 3.077871 respectively. The other methods such as ANN and GA can be used with fuzzy logic to improve its performance. Similarly, using more number of data-sets and supplementary variables, FIS would be even more enhanced. The model's prediction will be more enhanced if it is tried with other membership functions like bell-shaped, sigmoid trapezoidal and more number of data with distinct rule base.

Thus, effective forecast by the model specifies that FL is really a helpful modeling tool intended for engineers and investigators in the domain of concrete and cement. [24]
[4] S.-H. Han, J.-K. Kim, Y.-D. Park, Cement and Concrete Research 33 (2003) 965-971

[5] Gleize PJP, Cyr M, Escadeillas G. "Effects of metakaolin on autogenous shrinkage of cement pastes". Cement Concrete Compos 2007;29(2):80-7.

[6] Vu DD, Stroeven P, Bui VB." Strength and durability aspects of calcined kaolinblended Portland cement mortar and concrete". Cement Concrete Compos 2001;23(6):471-8.

[7] R. Siddique, Cement and Concrete Research 34 (2004) 487-493.

[8] K.G. Babu, G.S.N. Rao, Cement and Concrete Research 24 (1994) $277-284$.

[9] Akkurt S, Tayfur G, Can S. "Fuzzy logic model for prediction of cement compressive strength". Cement and Concrete Research. 2004;34(8):1429-1433.

[10] Demir F. "A new way of prediction elastic modulus of normal and high strength concrete-fuzzy logic". Cement and Concrete Research. 2005;35(8):1531-1538.

[11] Unal O, Demir F, Uygunog $`$ lu T. Fuzzy logic approach to predict stress-strain curves of steel fiber-reinforced concretes in compression. Building Environment. 2007; 42(10):3589-95.

[12] Topcu IB, Sarıdemir M. "Prediction of mechanical properties of recycled aggregate concretes containing silica fume using artificial neural networks and fuzzy logic". Computational Materials Science. 2008:42(1):74-82.

[13] L.A. Zadeh, "Fuzzy Sets", Information and Control, 1965, vol. 8, pp. 338-353.

[14] Z. S_en, "Combining Back propagations and Genetic Algorithms to train to train neural networks for Ambient Temperature Modelling", Solar Energy, 1998 vol. 63 (1), pp. 39-49.

[15] E.H. Mamdani, "Fuzzy Logic control of aggregate production planning", S. Assilian, International Journal of Man-Machine Studies, 1975, vol. 7, pp. 1-13.

[16] F.M. McNeill, "Application of Fuzzy Logic in Interior Daylight Estimation”, E. Thro, Fuzzy Logic: A Practical Approach, AP Professional, Boston, MA, 1994.

[17] G. Inan, and A.B. Goktepe, "Prediction of sulfate expancion of PC mortar using adaptive neuro-fuzzy methodology", K. Ramyar, A. Sezer, Building and Environment, 2007 vol. 42 (3), pp. 1264-1269.

[18] M. Sugeno, and G.T. Kang, "Fuzzy Sets Systems Man and Cybernetics", 1993, vol. 23 (3), pp. 665-685.

[19] K.M. Passino, "Stable Fuzzy Logic design of point to point control for mechanical systems", S. Yurkovich, Fuzzy Control, Addison-Wesley, 1998.

[20] D.W.C. Ho, and P.A. Zhang, "Design of Fuzzy Wavelet Neural Networks using the GA approach for function approximation and system"

[21] T. Takagi, and M. Sugeno, "IEEE Transactions on Systems Man and Cybernetics", 1985, vol. 15, pp. 116-132.

[22] J.S.R. Jang, and C.T. Sun, Proceedings of the IEEE vol. 83, pp. 378-405, 1995

[23] S. Akbulut, A.S. Hasilog $\varnothing l u$, and S. Pamukcu, Soil Dynamics and Earthquake Engineering, vol. 24, pp. 805-814, 2004.

[24] Sakshi Gupta, "Use of triangular membership function for prediction of compressive strength of concrete containing nanosilica", Cogent Engineering, 2:1025578, 2015.

[25] Paratibha Aggarwal, Yogesh Aggarwal, "Prediction of Compressive Strength of Self Compacting Concrete with Fuzzy Logic", World Academy of Science, Engineering and Technology

International Journal of Mathematical and Computational Sciences, Vol:5, No:5, 2011.

[26] C. Sivapragasam, G Vasudevan, P Vincent, P Sugendran, M Marimuthu, "Rule reduction in fuzzy logic for better interpretability in reservoir operation", Hydrological Processes: An International Journal 21 (21), 2835-2844,2007.

[27] C. Sivapragasam, P Sugendran, M Marimuthu, S Seenivasakan,

"Fuzzy logic for reservoir operation with reduced rules", Environmental Progress 27 (1), 98-103, 2008.

\section{REFERENCES}

[1] D.M. Suchorski, Aggregates For Concrete (ACI Education Bulletin, Atlantic, 2007)

[2] M. Abdullahi, H.M.A. Al-Mattarneh, A.H. Hassan, M.H. Abu Hassan, B.S. Mohammed, ICCBT. A.21, 231 (2008)

[3] M.C. Nataraja, M.A. Jayaram, C.N. Ravikumar, Eng. Lett. 13(2), 98 (2006) 


\section{AUTHORS PROFILE}

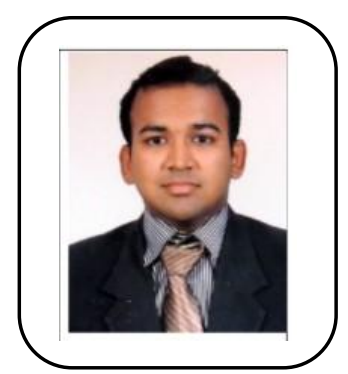

First Author Mr. M. Deepak. Assistant Professor, Department of Civil Engineering in Karpagam College of Engineering, Coimbatore, Tamil Nadu, India, areas of interest are Theory of Structures, structural optimization, Artificial Neural Network, fuzzy logic, etc. Worked in various in interdisciplinary projects .eager to learn new emerging concepts of Artificial Intelligence, Data Analytics, which would apply in day to day life of civil Engineer., have Publications in several scopus indexed Ineternational journals and conferences

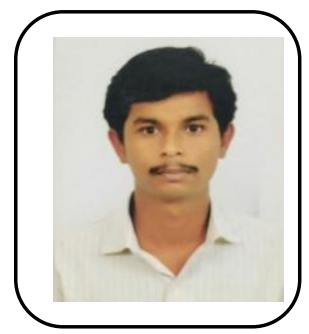

Second Author Balamurali M, a native of Tiruchirapalli, Tamil Nadu. He is pursuing final year of his Bachelor's degree in Karpagam College of Engineering, Coimbatore, Tamil Nadu, India. His areas of interest are design of $\mathrm{RC}$ elements, design of steel structures and concrete technology. He is having basic level of knowledge in softwares such as AutoCAD, Revit Architecture, STAAD Pro, QGIS. He is eager to learn new concepts and ideas in every field in his day to day life. He has participated in various workshops and presentations etc.

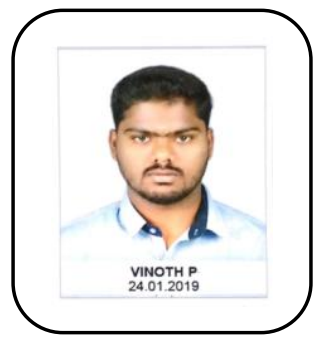

Third Author Vinoth $\mathrm{P}$ is from Krishnagiri, Tamil Nadu. He is pursuing final year of his Bachelor's degree in Karpagam College of Engineering, Coimbatore, Tamil Nadu, India. His areas of interest are design of RC elements, design of steel structures. He is having basic level of knowledge in softwares such as AutoCAD, 3DS MAX etc.

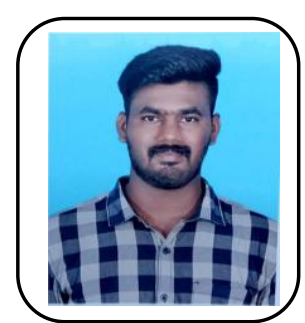

Fourth Author Jeeva Bharathi $\mathrm{J}$ is from Salem, Tamil Nadu. He is pursuing final year of his Bachelor's degree in Karpagam College of Engineering, Coimbatore, Tamil Nadu, India. His areas of interest are design of RC elements and planning. He is having basic level of knowledge in softwares such as AutoCAD, STAAD Pro etc.

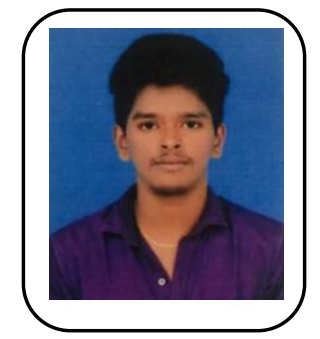

Fifth Author Kapil Aravindh K is from Rameshwaram, Tamil Nadu. He is pursuing final year of his Bachelor's degree in Karpagam College of Engineering, Coimbatore, Tamil Nadu, India. His areas of interest are designing, planning and safety management. He is having basic level of knowledge in softwares such as AutoCAD, ETabs etc. 